\title{
Security-driven distributed platforms for intellectual property resource provision - a case study of TSITE IP
}

\author{
Yang Wang (i)
}

\begin{abstract}
In the information age, with the vigorous development of big data and artificial intelligence, intellectual property protection is an essential part of the current scientific and technological development. Intellectual property related data grows in a geometric progression, so the demand for IP data storage space is also increasing day by day. With the rise of cloud computing technology, intellectual property data distributed platforms based on cloud storage have also been produced one after another. Because the biggest feature of cloud storage is that storage is a service, it puts forward higher requirements for the intellectual property service industry. Firstly, it introduces the domestic intellectual property cloud platform services from the perspectives of government support, state-owned enterprises and private enterprises; Secondly, four typical distributed platforms provided by commercial resources are selected to introduce their operation modes, focusing on the problems faced by domestic intellectual property service modes; Secondly, it compares and discusses the current situation of domestic intellectual property distributed platforms; Then, aiming at the current domestic intellectual property service mode, taking tsite as an example, this paper puts forward the design and construction strategy of intellectual property protection, intellectual property operation service distributed platform and operation service mode under the background of information age.
\end{abstract}

Keywords: Intellectual property, Cyber security, Privacy protection, Operation service, Distributed computing, TSITE

\section{Introduction}

In recent years, distributed IP resource delivery platforms and corresponding service delivery have become increasingly popular in China $[1,2]$. At present, people's understanding of IP resource services remains in the simple transfer, license, registration and application, protection and other direct access to commercial value. The theoretical research and practice of security-driven distributed intellectual property operation service is just at the beginning, and there is a lack of mature business model of intellectual property operation service based on cloud platform [3-7]. Because there are still loopholes in the implementation of the legal protection of intellectual

Correspondence:wy123126@sohu.com

School of Intellectual Property, Nanjing University of Science and Technology, Nanjing, China property rights, at the same time, China's industrial development also has its own unique technical path, coupled with the semi-open and semi-closed state of China's financial system, these three main aspects work together to make China's IP operation services grope ahead in different sub-markets. For example, in the face of intellectual property pledge financing, banks need enterprises to provide relevant physical assets as supporting guarantees. Facing intellectual property securitization, financial institutions are still cautious about substituting Special Purpose Vehicle (SPV) and its credit enhancement. As for the valuation problem, which is indispensable in all kinds of distributed intellectual property operation and service activities, each subject in the market holds its own opinion and cannot draw a unified conclusion. Although the future prospects are generally optimistic, the substantial promotion of security-driven distributed IP operation 
services has not made significant progress [8]. Different from the operation mode of IP, due to the dividend brought by the huge population base, the rapid development of digital technology and the strong imitation and innovation ability of Chinese enterprises [9]. In recent years, China's digital economy has been booming. Small to daily necessities, as well as work needs, large to the garage are frequent online transactions and transactions. Products with physical objects as carriers are easy to trade on the Internet because of their "tangible" characteristics $[10,11]$. However, it cannot prove that intangible services without physical objects cannot be sold online. For example, commercial insurance has been fully aware of online transactions. Based on this trend of similar comparison, various distributed platforms for IP operation services based on cloud storage have sprung up [12-14]. The intellectual property operation service platform described in this article is a commercial intellectual property management platform that integrates modern communication technology, computer network technology, and intelligent control technology. Therefore, this paper summarizes the development status of IP service and common distributed commercial digital service platform, and focuses on the design of IP service and distributed commercial digital service platform. At the same time, we take an IP resource management framework, TSITE IP as an example to discuss the construction methods and strategies based on distributed platform, the types of resource service modes and the future development direction. Among them, it focuses on the privacy security issues of potential information leakage of cloud platform, and puts forward the future development opportunities and challenges. This paper is organized as follows.

This paper summarizes the development status of IP service and common commercial digital service platform based on distributed, and focuses on the design of IP service and distributed commercial digital service platform. At the same time, we take an IP resource management framework TSITE IP as an example to discuss the construction method and strategy, resource service mode types and future development direction based on distributed platform. The purpose is to provide reference for the researchers of intellectual property platform technology and intellectual property platform service mode, so as to solve the problems existing in the current intellectual property platform, especially the cloud platform and service mode, and help the researchers understand the current intellectual property platform and service mode faster and combine with the technology development trend of the current era, provide research ideas for the development of intellectual property cloud platform.

The Intellectual property operation services investigates the mode of intellectual property operation and service, especially from the government, state-owned capital and private capital. The Business resource provision platforms introduces the general distributed IP operation and commercial digital service platform. The Discussion compares the Intellectual property operation services and the Business resource provision platforms respectively, analyzes the TSITE IP platform, and discusses the potential threats, challenges and future development prospects of the current security-driven distributed platform with a summary in Conclusions.

\section{Intellectual property operation services}

According to the profit model, the intellectual property operation and service platforms in the market can be roughly divided into the following three types: government, state-owned capital and private capital.

\section{Public IP operational services provided by the government}

The public IP operational services supported by the government is to build an IP operational services system with complete elements, sound system and smooth operational services [15]. It is constructed mainly from three aspects: improving the quality of IP creation, constructing the great protection pattern of IP and improving the whole chain service system of IP operational services. The government realizes that intellectual property operation services play an important role in the economy, industry, and innovation. Therefore, it fully releases the effect of comprehensive utilization of intellectual property rights and promotes economic innovation and continuous improvement of competitiveness. In recent years, many IP operational services with financial funds as the source of income have emerged through direct establishment and indirect support from the central government to the local government, most of them provide conventional public services such as patent navigation, while the online services only appear as digital tools and displays. Due to the support of the government, its original IP data resources are rich in the early stage, but the customer activity is very low except for the rigid application and approval. The operational services and maintenance parties of various services on the platform are mostly government dispatched agencies or third-party service agencies purchased by the government. Due to the increasingly strict financial system, most of these platforms show the situation that "there is no survival problem in the short term, but it is difficult to have a greater development" $[16,17]$.

\section{IP operational services owned by states}

State owned assets are the general name of all property and property rights owned by the state. The state is the only subject of the ownership of state-owned assets. Intellectual property rights - whether patents, trademarks, trade names, copyrights, trade secrets, new plant varieties, 
integrated circuit layout design, due to their property attributes, naturally belong to an important part of stateowned assets. As the operator of IP operational services, the capitalization operational system of IP is also built. The state-owned capital, which is composed of stateowned enterprises and collective enterprises, not only bears the characteristics of the general market main body responsible for its own profits and losses, but also bears more corporate social responsibility [18]. Due to China's special national conditions, the strength of state-owned capital is not only reflected in capital and assets, but also reflected in the response to national policies. First of all, it is reflected in the protection of IP rights. The protection of IP rights of state-owned enterprises refers to the strategies and measures for state-owned enterprises to protect and manage their own IP rights in accordance with the law, avoid possible harm, and obtain competitive advantages of IP rights. The construction of the intellectual property management system of state-owned enterprises is the basis and premise of the intellectual property management of state-owned enterprises and the implementation of the intellectual property strategy of state-owned enterprises. Specifically, it refers to the organic whole composed of the intellectual property policies and objectives of state-owned enterprises, the responsibilities of intellectual property management institutions and personnel, and the intellectual property management matters of all links of production and operation activities. As for the intellectual property management of state-owned enterprises, it mainly includes three aspects: asset management, risk management and basic management. However, there are some problems in the current IP protection, such as weak awareness, paying attention to the accumulation of tangible assets, ignoring the accumulation of intangible assets, and the loss of IP due to imperfect management. As the operator of IP operational services system, state-owned capital has two main starting points: to set up investment funds with strong capital strength, to invest in target enterprises with high-quality IP assets, or to provide industrial services with high-quality IP assets as target enterprises, and real estate assets, including industrial real estate, represented by heavy assets and goodwill. Despite the emphasis on IP, it is undeniable that the IP operational services with state-owned capital as the operator pays more attention to the appreciation potential outside the IP in the target enterprise [19]. However, compared with the public IP operational services system supported by the government, taking the product popularity as the index, it is a step forward to the road of marketization. Therefore, the first mock exam of the new mode of state capital integration of production and finance is put forward by more and more state-owned enterprises: this mode is a business mode of "four in one + fund". "Four in one" refers to the four roles of government, industry, state-owned enterprises and financial institutions. As an industry finance integration platform, state-owned enterprises connect the needs and resources of all parties, provide professional services, give full play to the two advantages of government and market and the respective advantages of various stakeholders, transform the intention of government and state-owned enterprises into market realizable solutions and reduce risks. On the one hand, the "fund model" enlarges the guiding function of stateowned capital, on the other hand, it can flexibly design risk solutions according to the asset risk level to meet the capital investment needs of different risk preferences in the market.

\section{Private IP operational services}

Private capital as the operator to build IP operational services system. With the vigorous promotion of IP operational services at the national policy level, private capital smelling various business opportunities has appeared in the form of platforms $[20,21]$. The state adopts various ways to strengthen the protection of IP rights of private enterprises. The state vigorously develops laws and regulations on IP rights, protects IP rights through laws, protects the legitimate rights and interests of the subject of IP rights, strikes illegal acts through laws, ensures the smooth operational resources of the IP market, and promotes economic development. People's enthusiasm for creation and invention is also promoted. At the same time, we should expand the proportion of private enterprises, improve the one-stop service mechanism of rapid authorization, confirmation and protection of rights, expand the financing coverage of IP pledge of private enterprises, reduce the financing cost, and guide the innovation and development of private enterprises. Based on the flexibility of private enterprises, their business model is also booming. At present, there are two most distinctive representatives: IP agency. Although IP agency business is the most basic part of the industrial chain, it is also the most mature operational mode. As the main operator of this mode, IP operational services only serve its closedloop business with symbolic meaning and plays the role of attracting customers. Second, with the development of digital technology such as team and technology, we should fully tap the implied information of IP rights in the form of legal texts. This mode provides services for customers in the form of big data reports. However, due to the use habits of customers and the market is still in its infancy, there is no leading enterprise in the industry. Regardless of the operating mode, most of China's private IP operational services pursue government subsidies [22, 23].

\section{Business resource provision platforms}

With the continuous development of cloud computing, cloud storage derived from it has also been applied in 
intellectual property data management. The framework technology for building cloud storage system is becoming more and more mature. The relevant enterprise intelligent cloud storage based on cloud platform can realize the functions of data storage and management for users. Among them, the biggest advantage is to help enterprises build their own private cloud, Realize the unified and centralized management of software and hardware resources, monitor the system in real-time, and provide user access control and other characteristic functions. This part selects four knowledge driven distributed business resource intellectual property service platforms, expounds, analyzes and discusses the business services they provide, and summarizes the current situation of the current platform. The specific contents are as follows.

\section{SIPOP}

The state intellectual property operation public service platform (hereinafter referred to as "SIPOP") is an important work deployment power of "accelerating the construction of national intellectual property operation transaction and service platform and building intellectual property" according to the national "13th five-year plan" [24]. This is a pilot project led by the State Intellectual Property Office and jointly initiated by the Ministry of finance. It is the core of the national " $1+n$ " intellectual property operation system. It takes the intellectual property operation organization as the node to realize the interconnection of business flow, information flow and capital flow, and build a platform operation network with unified rules and all over the world. The national intellectual property platform mainly provides three navigation services: innovation, application protection and service management. The core carrier will provide platform support for patent transfer and transformation, acquisition and custody, transaction flow, pledge financing and patent navigation, so as to improve the efficiency of patent application rate. At the same time, it provides a one-stop platform with intellectual property services as the core solution. As shown in Fig. 1, the related services provided by the national platform are characterized. It is worth mentioning that we provide special services such as patent writing quality assistance, patent subsidy, expert database, intellectual property training, patent filing, certification inquiry, etc.

\section{IPOnline}

IPOnline is a "Internet plus intellectual property operation public service platform" established by Beijing intellectual property management and Management Co., Ltd. (hereinafter referred to as "Beijing intellectual property" or "Zhongguancun intellectual property operation public service platform"), with the collection, storage, management and operation of patent assets [25]. It is an intellectual property operation service system with " $1+2$ $+n$ " characteristics. The platform gathers global innovation resources, provides property rights services, and

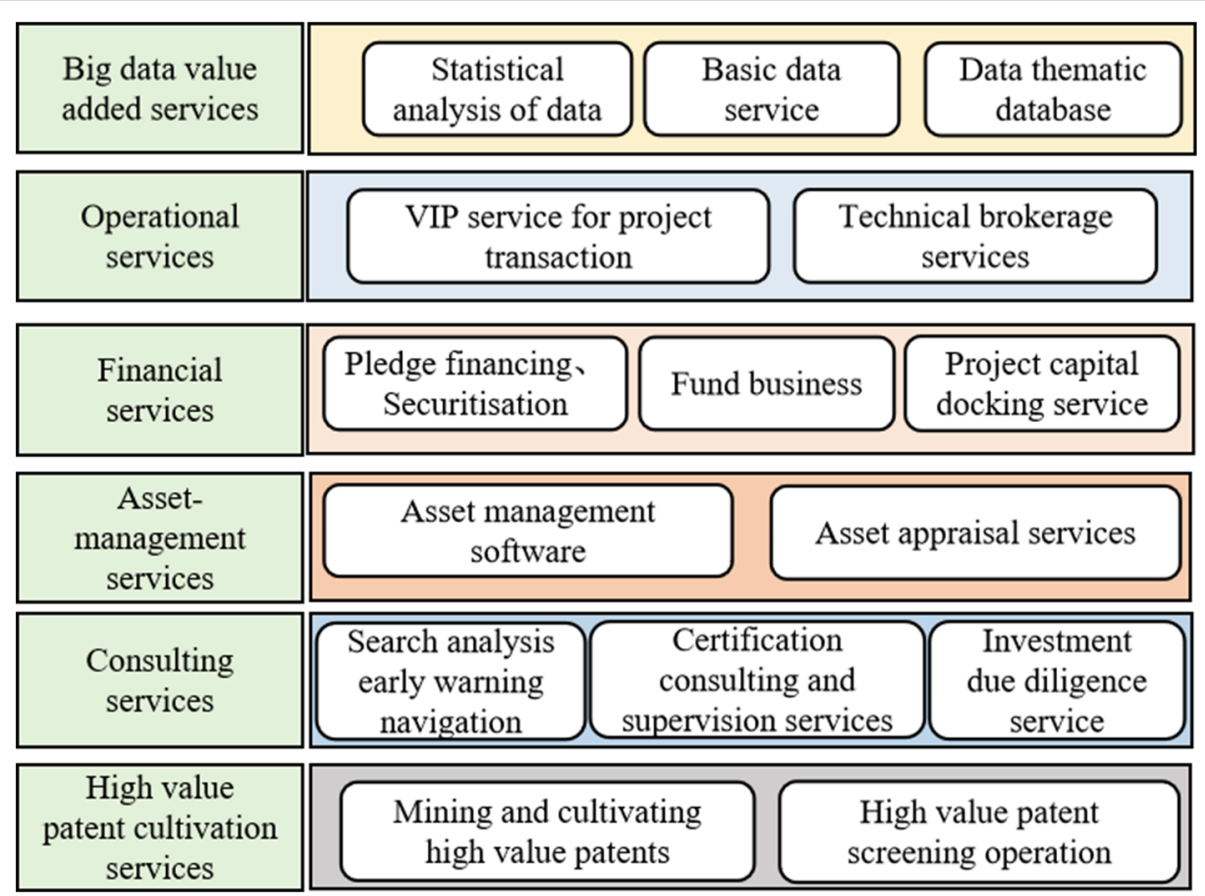

Fig. 1 Commercial Resource Management and Service Provision of SIPOP 
gathers domestic and foreign expert resources and IP community services of service resources. As shown in Fig. 2, it mainly integrates resources to build a collaborative service platform for intellectual property operation. It includes two business modules, intellectual property business services and financial services, providing product patent pools, SPV intellectual property rights operation, Internet plus intellectual property operation, intellectual property pledge financing, equity financing, advanced technology and other functional services. The platform is also a major achievement of the "ZhongGuanCun model", leading the innovation and development of intellectual property rights, and providing the government with the basis for statistical analysis and decision-making of patent operation data [26-28].

\section{CIPRUN}

Ciprun Group Co., Ltd. covers cross industry, technology, commerce, patents, trademarks, brands and other intellectual property and talents, and is led by a team with cross enterprise business experience [29, 30]. Currently, he is a member of China intellectual property development alliance. As shown in Fig. 3, the services involved are intellectual property rights, e-commerce, Internet + (intellectual property rights online services), intellectual property transactions (trademark trading, patent transactions, copyright transactions, international transactions), intellectual property management (big data, intelligence analysis), early warning analysis, management training, intellectual property financing (assessment, mortgage, guarantee, financing, securitization, business mode). Through the intellectual property services of these four departments, we can solve the intellectual property problems such as trademarks, patents and copyrights of enterprises and individuals, and form a complete ecological community of intellectual property rights such as intellectual property application, retrieval, monitoring, operation (transaction license), management, information intelligence, data analysis, evaluation, mortgage loan, achievement transformation, software research and development, publicity and training [31].

\section{TSITE}

TSITE is a technology innovation company founded in 2009, originated from Nanyang Polytechnic University in Singapore [32]. It officially entered the Chinese market and was registered in Hong Kong in 2012. TSITE believes that business information is a tacit knowledge, so its main business is to provide Chinese mainland enterprises with various commercial resources including market orders, venture capital and innovative technology through knowledge dissemination. After nearly 10 years of development, by 2020 , China Thailand group has established a trading mode provided by commercial resources and has a large number of small and medium-sized enterprise customers. TSITE group has accumulated a lot of commercial resources, and finally formed those mentioned above online and offline interwoven business network. Based on the advantages of its own business type and operation mode, the development trend of independent intellectual property and its operational service is determined. Based on the judgment of the direction of the development of China's intellectual property operation service format and its own business attributes and advantages,

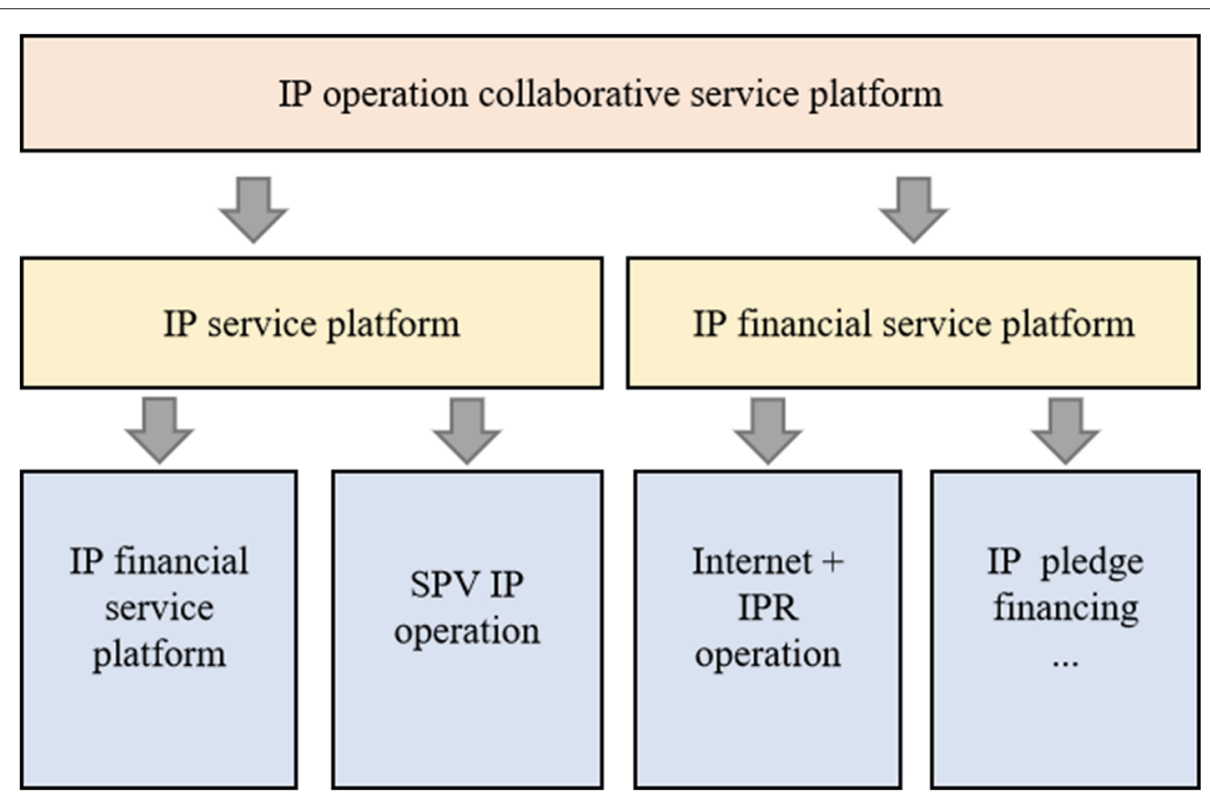

Fig. 2 IP Operation Collaborative Service Platform of IPOnline 


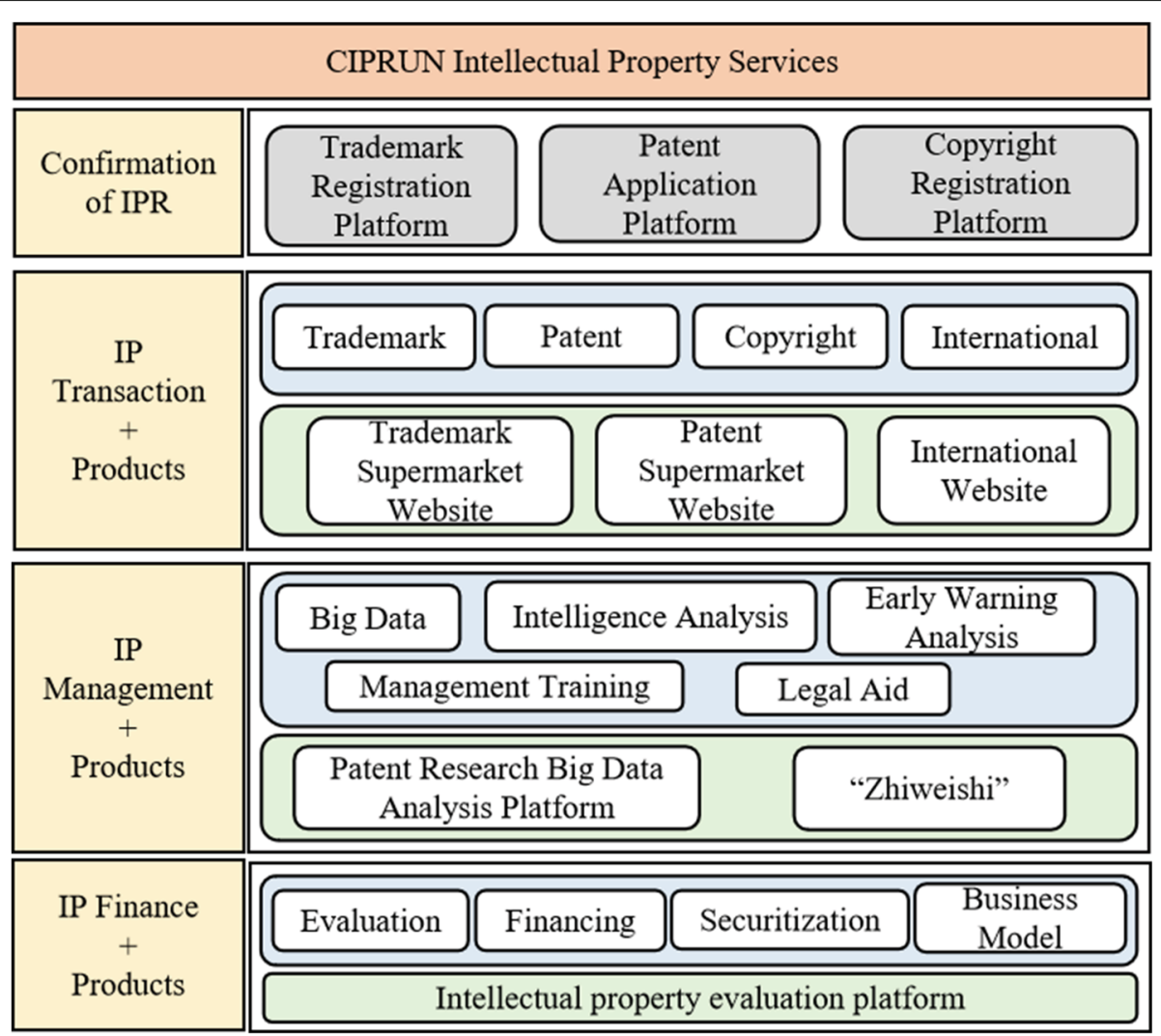

Fig. 3 CIPRUN Intellectual Property Services

TSITE group designed and established its intellectual property operation service platform TSITE IP, referred to as tip. The starting point of the design of the operation mode of TSITE intellectual property operation service platform is the Commission mechanism and customer service derived from the high-profit margin of intellectual property agency companies in the market. Figure 4 describes the basic operation mode, platform features and cooperation mode of TSITE intellectual property operation service platform. Through cooperation with a large number of existing intellectual property operation service companies, we can get a high commission and establish our own brand by providing essential value-added services for customers free of charge.

The TSITE IP application is developed based on the Serverless back-end to implement Serverless logic running in a stateless computing container. It is triggered by events and is completely managed by a third party. The platform is developed based on this technology, and its business-level status is recorded by the IP database and storage resources used by the developers. Serverless covers many technologies, divided into two categories: FaaS (function as a service) and BaaS (backend as a service). FaaS implies that you can directly run the backend code of TSITE IP applications without the need to manage server systems or personal server applications. BaaS implies that there is no need to write or manage all server-side components, and the domain public remote components are used to provide patent search services. The purpose is to allow users to focus only on their own business logic. Some security issues, such as the sudden increase of users, automatic capacity expansion and other resource scheduling issues, are entrusted to the cloud provider. The Serverless architecture of this platform is shown in Fig. 5. Only when the user initiates a request, the function will be activated and executed, thereby saving costs. It consists of two parts: bottomlevel services, which implement back-end microservices for complex businesses, such as Web crawlers, component calls, etc.; bottom-level services, which implement backend microservices for complex businesses. FaaS layer online coding realizes patent retrieval, video streaming media playback and other business logic through a series of functions, and directly provides services for the front end. At the same time, no matter in the back-end, FaaS or front-end, BaaS services provided by the cloud computing platform can be called, which greatly reduces the difficulty and cost of development and solves the problems of high availability and high availability. Concurrency and operation and maintenance. 


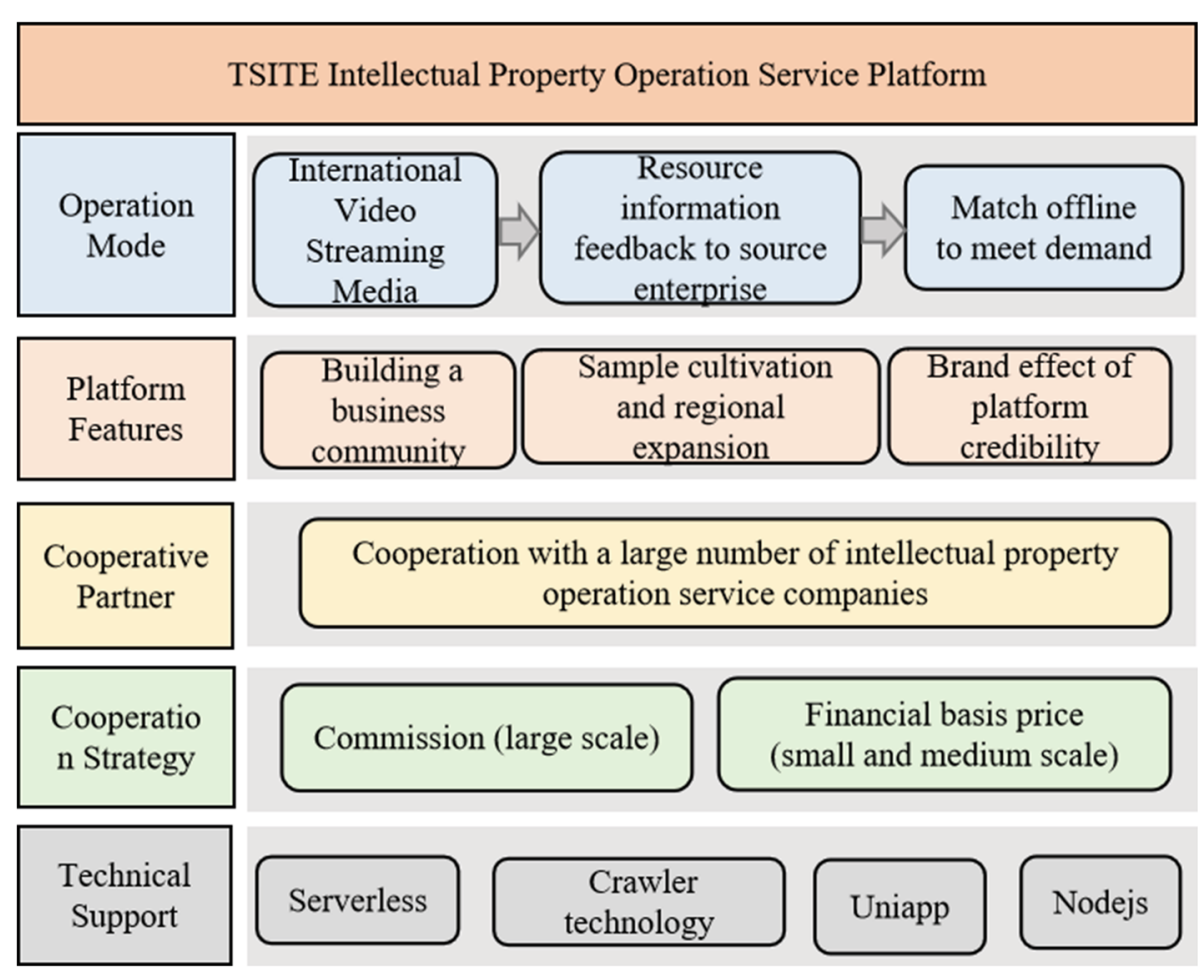

Fig. 4 TSITE Intellectual Property Operation Service Platform

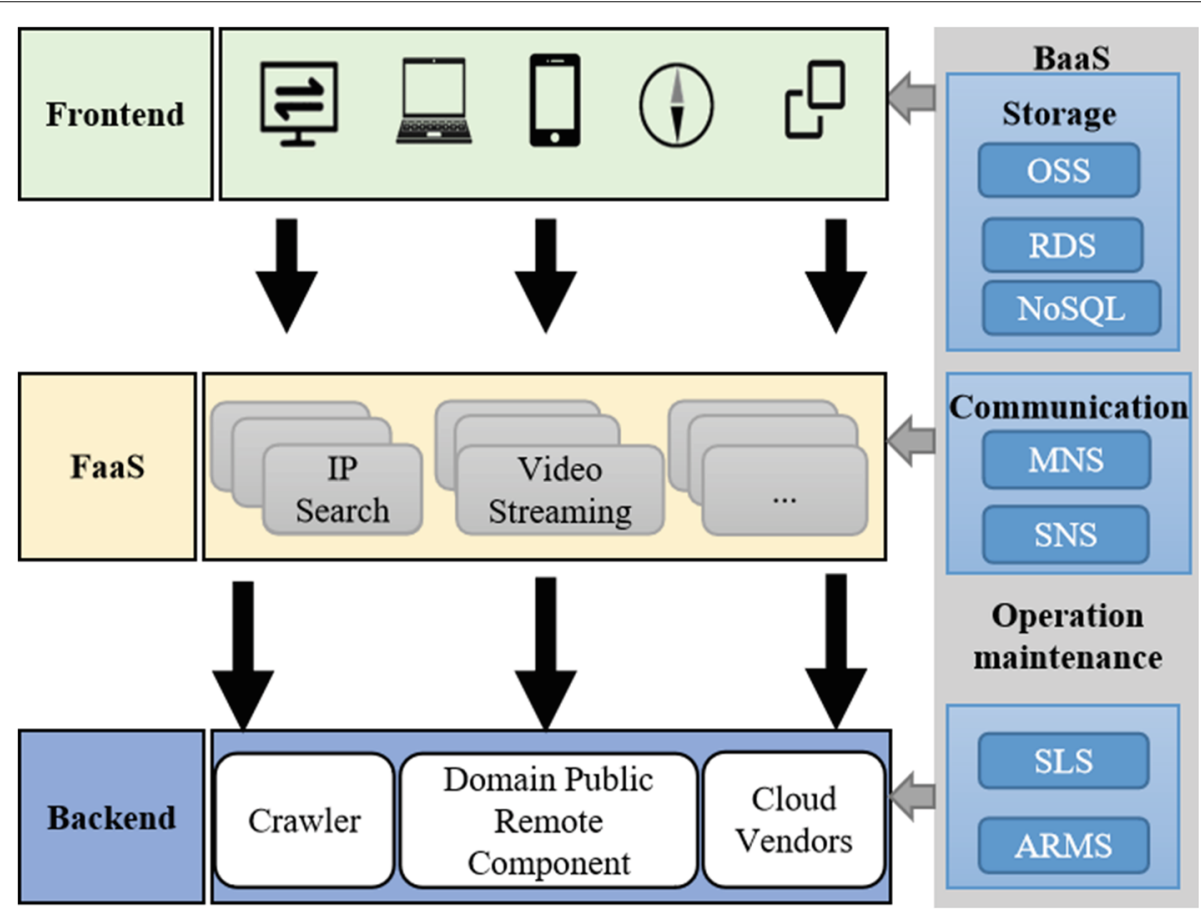

Fig. 5 The Structure of the Serverless Design 


\section{Discussion}

No matter what kind of business form of intellectual property operation service mentioned above, it does not shine as brilliantly as digital technology in life service industry $[33,34]$. At the macro-level, we think that the reason why the development of China's intellectual property operation services will encounter so many difficulties is that the development stage of China's intellectual property operation services is still in the early stage. Although China's intellectual property operation service format has the advantage of late development, compared with the development experience of western countries for hundreds of years, the unique national conditions and decades of development have not formed corresponding accumulation. This section mainly analyzes from the microlevel, specifically from three aspects: the comparison of intellectual property operation services, the comparison of commercial resource providing platforms, and the design strategy of intellectual property and commercial platform.

\section{Comparison of current intellectual property operation services IP legal support services}

In the aspect of the legal construction of intellectual property rights, although China has achieved the goal of "having laws to abide by", considering the overall development and local interests, there is still a long way to go in terms of "laws must be followed, law enforcement must be strict, and violations must be prosecuted". Firstly, the legal means is that the responsibilities of departments are permitted, and secondly, illegal acts must be dealt with according to the law. Among them, the necessary administrative means is to solve the administrative vacuum in the fields not covered by the current laws and regulations. For example, various management methods have been upgraded to laws and regulations [35]. Intellectual property is a systematic project. We should solve the specific problems of intellectual property development with system engineering thinking. In the construction of engineering projects, the legal relations involved in the acquisition and ownership of intellectual property rights, the infringement and response of intellectual property rights are very complex, which requires the active provision of intellectual property legal services. Therefore, lawyers play an irreplaceable role in this process. Hou [36], from the perspective of legal construction of computer software intellectual property rights, concluded that the improvement process of China's laws and regulations has always lagged behind the reform speed of information technology. However, the current spread of pirated software has not been subject to sound legal constraints and sanctions, which will certainly affect the development of the information industry, and the development of China's intelligent process and artificial intelligence. Therefore, the legal protection of computer software intellectual property is urgent, necessary and long-term. The legal system of computer software intellectual property must be established as soon as possible. Lou took artificial intelligence as the core, and discussed the challenges and impacts of artificial intelligence on the legal protection of intellectual property rights and the legal system framework from three aspects of legal relationship theme, behavior and evaluation [37]. It is pointed out that the current knowledge legal system does not consider the relevant legal evaluation of artificial intelligence, so it is difficult to evaluate the invention and creation behavior of artificial intelligence fairly and reasonably, which leads to contradictions and conflicts. It is concluded that we should correctly understand and explain the challenge of artificial intelligence to intellectual property protection under the framework of the existing intellectual property law system, and strengthen the theoretical research on the legislative level to improve the intellectual property protection system mainly based on artificial intelligence.

Through the above, there is still a lot of room for refinement and improvement of the current intellectual property law construction. For example, under the comprehensive law of the intellectual property protection law, the current patent law, trademark law, copyright law and other relevant intellectual property separate laws can be amended and formulated accordingly.

\section{Focus of specific scenarios}

In the specific industries involved in intellectual property rights, although China has established the most comprehensive industrial system in the world, there is still a gap between "large and comprehensive" and "strong". If the discourse power of many high-tech industries is not in China, the operation of intellectual property rights cannot be smooth in the industrial chain. Of course, this situation is also gradually changing, such as the $5 \mathrm{G}$ industry [38]. Under the wave of 5G, Huawei has become the largest supplier in the world, and China's technological and economic status has leapt thousands of miles to the forefront of the world. Strengthen the protection of intellectual property rights, as the backbone of $5 \mathrm{G}$ technology development and the premise of ensuring all technological breakthroughs and smooth operation. However, at present, due to the initial stage of 5G construction, the cost of a base station is significantly higher than that of 4G. In order to reduce the construction cost, it is the development direction in the future not to allow operators to build jointly. However, the interests of different enterprises are involved, and the ownership of intellectual property rights of the scientific and technological innovation achievements thus generated has not been given due attention [39-41]. 


\section{IP financial support services}

In the aspect of financial system construction, it is necessary to set up red line areas, such as the establishment of SPV [42]. Such red line areas are closely related to the high-end operation of intellectual property rights. Intellectual property is the strategic resource of national development and the core element of international competitiveness. Finance is the core of the modern economy. Intellectual property finance is an important part of intellectual property operation ecology, which will provide important support for the innovation and development of intellectual property work. China has carried out a lot of exploration in financial support for scientific and technological innovation, and initially formed a financial service system of scientific and technological innovation with a wide range of fields and various ways. But on the whole, China's existing financial service system has not formed an effective technological innovation orientation, which is far from meeting the practical needs of enterprise technological innovation development. Especially in the high-end operation of intellectual property. Intellectual property finance is the integration of intellectual property and financial resources. Its main forms include intellectual property pledge financing, patent insurance, intellectual property securitization, etc. However, there are defects in various forms, such as lack of intellectual property pledge financing, imperfect patent insurance system and so on $[43,44]$.

\section{Comparison of business resource provision platforms}

This section mainly compares the services provided by the four commercial resource platforms mentioned in the third section, and selects several special indicators for comparison. As shown in Table 1.

In Table 1, on the whole, the intellectual property value evaluation, intellectual property financial services and legal services of the commercial resource providing platform are basically available, which are obtained through the platform's self-operation and cooperation with thirdparty institutions. Horizontally, among the five functional indicators, SIPOP does not include video streaming media function, IPOnline does not include IP authentication query, STIS and video streaming media function, and CIPRUN does not have video streaming media function. TSITE has no STIS function. Vertically, in terms of IP authentication query indicators, only IPOnline does not have this function indicator. In terms of science and technology information services, SIPOP and CIPRUN have this service function. However, international video streaming media is only available on the TSITE platform, and it is also the primary operation mode of the TSITE platform. It is worth noting that TSITE has accumulated rich resources and experience by providing customers with basic value-added services free of charge. Combine resources, experience and intellectual property thinking to form an online communication mode of international video streaming media, and carry out corresponding offline matching to meet the needs of enterprises.

\section{Design strategies of intellectual property operation and commercial platforms}

In the design of the intellectual property operation service platform, the intellectual property operation service should be defined as a commercial service: the business

Table 1 Comparison of Business Resource Provision Platforms

\begin{tabular}{|c|c|c|c|c|c|c|}
\hline Name & $\begin{array}{l}\text { IP certification } \\
\text { query }\end{array}$ & $\begin{array}{l}\text { Evaluation of } \\
\text { IP Value }\end{array}$ & IP Finance & STIS & Legal Service & $\begin{array}{l}\text { Video } \\
\text { Streaming } \\
\text { Media }\end{array}$ \\
\hline SIPOP & $\begin{array}{l}\text { detailed, } \\
\text { transparent and } \\
\text { open, } \\
\text { comprehensive }\end{array}$ & $\begin{array}{l}\text { Cooperate; } \\
\text { evaluation and } \\
\text { analysis services }\end{array}$ & $\begin{array}{l}\text { "Zhirongbao", } \\
\text { "Zhishan loan", } \\
\text { "Zhi credit" and } \\
\text { "Zhongchuang } \\
\text { and Zhibao" }\end{array}$ & $\begin{array}{l}\text { information } \\
\text { service }\end{array}$ & $\begin{array}{l}\text { patent litigation } \\
\text { products }\end{array}$ & / \\
\hline IPOnline & / & $\begin{array}{l}\text { Customized } \\
\text { service }\end{array}$ & "zhirongbao" & / & $\begin{array}{l}\text { Cooperation with } \\
\text { law firms }\end{array}$ & / \\
\hline CIPRUN & $\begin{array}{l}\text { ISO system, CCC, } \\
\text { CE, ITSS, credit } \\
\text { evaluation }\end{array}$ & $\begin{array}{l}\text { consultation, } \\
\text { analysis, risk early } \\
\text { warning, value } \\
\text { evaluation }\end{array}$ & $\begin{array}{l}\text { Asset } \\
\text { appraisal,real } \\
\text { estate } \\
\text { management } \\
\text { services, mort- } \\
\text { gage,guarantee }\end{array}$ & $\begin{array}{l}\text { online } \\
\text { management of } \\
\text { "Zhiweishi" }\end{array}$ & $\begin{array}{l}\text { online } \\
\text { management of } \\
\text { "Zhiweishi" }\end{array}$ & / \\
\hline TSITE & $\begin{array}{l}\text { Cooperate with a } \\
\text { large number of } \\
\text { IP service } \\
\text { companies }\end{array}$ & $\begin{array}{l}\text { Cooperate with a } \\
\text { large number of } \\
\text { IP operation } \\
\text { service } \\
\text { companies }\end{array}$ & $\begin{array}{l}\text { Cooperate with a } \\
\text { large number of } \\
\text { IP operation } \\
\text { service } \\
\text { companies }\end{array}$ & - & $\begin{array}{l}\text { Cooperation with } \\
\text { law firms }\end{array}$ & $\begin{array}{l}\text { Resources are } \\
\text { combined with } \\
\text { experience and IP } \\
\text { thinking }\end{array}$ \\
\hline
\end{tabular}


attribute should be enhanced by human empowerment to facilitate the exchange between the platform and users. This kind of exchange should be a direct exchange rather than a converted indirect exchange, which explains why fund and big data are feasible but developing slowly: indirect exchange reduces its exchange efficiency. Direct exchange comes from the needs of users, that is, the closer the intellectual property operation services provided are to the customers' needs, the higher the exchange efficiency will be. Through the visit and investigation of hundreds of experiences distributed in various regions of China, it is concluded that the specific needs of the top three enterprises are: customers, financing and technology. Customers' purchase of products or services is the fundamental factor for enterprises to maintain positive cash flow. The amount of financing is positively related to the theoretical range of enterprise development. Technological innovation makes enterprises form core competitiveness that cannot be surpassed by peers in a short period of time. The relationship between the specific needs of these three enterprises and intellectual property rights is indirect. In order to bridge in many directions, it is necessary to set up a media with mass attributes artificially. This kind of media is different due to different genes of operators of intellectual property operation service platforms.

Taking TSITE group as an example, this section introduces the design strategy of intellectual property operation service from four aspects: international video streaming media based on business demand, classification of enterprise audience and establishment of the regional and industrial business community, brand effect of regional expansion and strong planning, and government empowerment and platform credibility brand construction.

\section{International video streaming media based on enterprise demand for commercial resources}

TSITE group (HK) Co., Limited is a kind of video streaming media which is produced by intellectual property and spread internationally. TSITE group has been engaged in the economic matching business in the fields of financing, market and technology for many years, and has accumulated a lot of resources and experience. First of all, combine these resources with experience and intellectual property thinking to form an international video streaming media mode for online transmission, and then accurately feedback the resources and information obtained after transmission to the source enterprises. Finally, the corresponding offline matching is carried out to meet the needs of enterprises. The series of the trilogy not only meets the needs of intellectual property agency companies to provide high-quality additional services at the same time, it also constitutes the basic operation mode of TSITE intellectual property operation service platform. In the basic operation mode of TSITE intellectual property operation service platform, how to use very low cost to produce high-quality international video streaming media on a large scale and make it spread in the entire platform ecosystem is the premise.

At present, the production cost is very high, and the only choice to achieve low cost, high quantity and high-quality output is to fully adopt the combination of standardized production and crowdsourcing and crowdfunding. On the one hand, TSITE intellectual property operation service platform uses the internship system of vocational colleges to set up a video shooting and editing production team to reduce costs in the way of standardized production, and the team composition includes shooting editing and participating in communication; on the other hand, the platform makes full use of cross-regional crowdsourcing and crowdfunding of digital technology to solve the problem of team coverage, and the specific methods include service outsourcing and joint construction. International video streaming media adopts English interpretation, supplemented by Chinese subtitles, with the standard "TSITE Intellectual Property Operation Service Platform” format of the title and ending, and interprets the enterprise information of financing, market and technology with the thinking of intellectual property operation. In order to ensure the reading quality of the audience, the time of a single national video streaming media will be strictly controlled within 6 minutes. After the international video streaming media is made, the online domestic channel is TSITE official we media matrix, and the online international channel is TSITE organizational international website established in Singapore (www.t-site.org). The offline domestic channels are local government departments of economic development and scientific and technological talents, investment and financing institutions and efficient scientific research institutes. The offline international channels are science and technology, economy and culture departments of Consulates General of Europe, America, Japan and South Korea in Shanghai, chambers of Commerce of various countries in Shanghai and nongovernmental exchange organizations.

\section{Classification of enterprise audience and establishment of regional and industrial business community}

In the enterprises that the intellectual property operation service platform is facing, it is classified according to whether they have intellectual property (including invention patent, utility model, design, software copyright and trademark, etc.). For enterprises with intellectual property rights, the platform adopts the way of public welfare subsidies to produce international video streaming media for them to express their demands and disseminate their information. In the process of mutual integration and knowledge exchange, the higher demand for business 
innovation based on intellectual property will be mined and digested, which is one of the initial profit models of the platform. For the enterprises that have not owned the intellectual property rights, the platform will package its intellectual property solutions with international video streaming media on the principle of incremental no price increase, so as to realize the feedback of the platform and cultivate the awareness of intellectual property rights of enterprises to help them innovate. Based on the criteria of regional and industrial distribution, the cross distribution of business interests and knowledge flow will be formed. Some enterprises in the same region unite to form a largescale cost reduction, and enterprises in different regions complement each other in various resources to expand scalability. The collaborative innovation of the upstream and downstream enterprises in the industrial chain, and the enterprises in the branch chain optimize the industrial environment. In the above-mentioned economic and cultural knowledge exchange activities, TSITE intellectual property operation service platform will become the hub of various needs, information flows and resources, and will be located in the core position of the entire ecosystem with intellectual property as the theme. The platform can not only digest all kinds of needs by itself, but also organize crowdsourcing or crowdfunding for marketization, so as to achieve economic benefits while solving enterprise problems.

\section{The brand effect of regional expansion and strong planning}

No matter what kind of content is based on, one of the most significant characteristics of digital online platform is that it can break through the limitation of physical space, provide services for all kinds of subjects on the platform and form feedback interaction. From the perspective of the regional distribution of the main body, we can find that the larger the scope of the regional distribution, the stronger the complementarity between similar subjects and various subjects. From the technical route of platform development, we can find that the faster the scale is formed, the lower the marginal cost of platform operation and the stronger the stability. In the initial stage, TSITE intellectual property operation service platform parallels the sample cultivation and regional expansion by taking the region as the unit: the sample cultivation provides a good demonstration for regional expansion and attracts the subjects from different regions to enter into it. The regional expansion not only provides a strong resource support for the platform policy source, but also has beneficial knowledge exchange for the platform based on the development experience of foreign countries. In an era when form and content are equally important, it is necessary for platform engineering to continuously export valuable products, services and solutions in the most appropriate way and form a brand. This so-called most appropriate way is a processed content generated information flow in line with the current reading habits. On the TSITE intellectual property operation service platform, it is the knowledge output based on the international video streaming media mentioned above.

\section{Government empowerment and brand building of platform credibility}

The strong support of the relevant government departments represented by the Intellectual Property Office for the development of the intellectual property operation service platform is not only the background of the birth, growth and development of the series of intellectual property operation service platforms, but also endows great energy for the brand construction of the platform's credibility. According to the field visit and investigation of the State Intellectual Property Office, the competent authorities are very familiar with the difficulties and myths encountered in the development of the current intellectual property operation service platform. However, based on the role positioning and system constraints, it can only provide indirect support in the aspects of environment creation, so as to avoid breaking the market mechanism. TSITE intellectual property operation service platform is different from the existing similar platforms driven mainly by investment or big data. Its strong commercialization and landing are directly related to the hot issues of financing, market and technology, which are concerned by relevant government departments. Therefore, it is easier to obtain resource support from multiple government departments. By using powerful government resources, taking the basic intellectual property agency as the unit starting point, closely following the financing of end customers, market and technical requirements, and strong planning, the international video streaming media will spread, and the eventually established ecosystem will have a strong brand appeal. In this brand appeal, the relevant intellectual property operation service platform can create corresponding economic and social value.

\section{Opportunities and challenges from enabling technologies}

In the era of mobile Internet, the development of securitydriven distributed operation service platforms has shown a good trend, and the development of resource coordination and service configuration has gradually stabilized. In order to enhance the core value and competitiveness of the platform and create a comprehensive IP service platform, the IP operation platform needs to be based on its own resource advantages, deeply grasp the characteristics of the target needs, provide users with content that conforms to the trend of informatization, and increase configuration methods. Realize intelligent communication 
between all parties. In order to meet these requirements, the current operating platform development still faces challenges.

\section{Cloud and edge computing}

In the Internet environment, cloud platforms have huge potential and are the mainstream of development. The TSITE cloud platform is realized through the synergy of relevant functional information of digital enterprises to realize data sharing and collaboration during the project cycle. All projects are scattered in major industries. The unified planning of the specific results of IP is an important factor for commercial products to gain market share. This will provide a scientific basis for the management and development of the enterprise. However, the resource allocation of TSITE platform is still in individual task mode, and most platforms still lack IP resources that emphasize collaboration and sharing. How to deploy the architecture in the cloud platform environment, manage the cloud service-oriented platform system, and at the same time control the platform authority classification, ensure the quality of platform resources, and carry out effective integration, which is a big challenge. In future research, cloud service platforms will become mainstream, and their service functions will become more and more mature. In the Internet era, the amount of data generated by intellectual property operation platforms has exploded, and data applications are distributed in various geographical locations. In the Internet era, the amount of data generated by the intellectual property operation platform is increasing explosively, and the application of data is distributed in various geographical locations. When information is stored in the cloud platform, enterprises can reduce the use of infrastructure and reduce the cost through less hardware. Enterprises no longer need to operate and manage their own center. Investing in cloud computing has become a more dynamic business model. At present, most digital Internet of things platforms rely on cloud computing technology, and cloud computing has become the main trend of current and future development. Although the cloud service platform provides efficient services, the current network bandwidth cost is high, the network environment is complicated, and the network delay is caused, which makes it difficult to further improve the efficiency of the cloud service platform.

In this context, the arrival of new edge computing technology may overturn the dominant position of cloud computing. And, edge computing has gradually been applied to operational service platforms [45, 46]. Edge refers to the edge of the network, computing and storage resources are relative to the data in the data center. Compared with data centers, the edge of the network is closer to users at geographic distances. The operating platform uses edge computing to provide technical services for users near the data source, and is committed to independently building its own operating service system. It can not only alleviate the high demand pressure caused by massive data on network bandwidth, but also speed up the response speed of the business and enhance the responsiveness of the business. At present, there are relatively mature edge computing platforms that have achieved good applications and development in some fields. However, in the actual application of the intellectual property operating platform, there are still many issues that need to be studied $[47,48]$. First, how to solve the problem of resources scattered among multiple subjects, such as the management and control of their own resources by users, network and operation service platform providers, and centralized management of resources that are different from cloud platforms for each subject, which also involves the main body of resource management, and the introduction of intermediate services when resource supply and transportation needs. However, the functions provided by this intermediary service method are limited and cannot meet other special needs [49]. Therefore, how to solve the problem of resource decentralization and flexible application is worthy of further study. Another problem is to solve the mobility of the geographic location of the user application operating platform, because each node of the edge computing serves the surrounding users. Once the geographic location changes, the corresponding service node needs to be switched. At this point, it is necessary to quickly match the available resources around and switch through the application location. How to meet the heterogeneity of resources and the diversity of network bandwidth, and to carry out effective resource exchange is also a major research difficulty. The next important issue is that virtualization technology also needs to be studied. Therefore, it is necessary to select the appropriate virtualization technology to perform edge computing on the operating platform. At the same time, virtualization technology cannot impose too many constraints on the environment, so as to maximize the use of medical resources and achieve more service requests. Data analysis is also a key issue in the development of edge computing. After analyzing and processing each subject resource, it is necessary to extract effective information. However, the number of computing nodes in edge computing is huge, and the existing common data analysis methods are not suitable for edge computing on operating platforms. As a new computing service model, edge computing still faces a series of challenges.

\section{Knowledge engineering}

TSITE IP team understanding of the operational services of IP is not limited to the simple direct acquisition of commercial value. At the same time, it cooperates with a large number of existing IP operational service companies 
to provide value-added services for customers. Its advantages are user resources and IP system engineering management support system. In the construction project, the related attributes and relations of IP and the legal relations involved are very complex, so it is necessary to effectively manage and utilize the resources to transform the multi-resource into realistic productive forces. Due to the influence and restriction of organizational mode, management level and complexity of relationship, specific strategy guidance has not been implemented yet.

Knowledge engineering relies on the current environment of big data and Internet to mine the association of information resources to the greatest extent, and stores the data in the formatted form in the computer as the established knowledge, which is convenient for management and utilization, and improves the efficiency of resource management in all aspects. There is no available knowledge engineering database in the IP operational service platform, and there are cold start challenges for the construction of knowledge engineering platform in specific fields. The construction methods are top-down and bottom-up. Top-down refers to first defining all the concepts and corresponding data resource patterns existing in the project, and then adding the annotated entity data into them. Bottom-up refers to the extraction of data from existing resources, the selection of some data into the project, and then the top-level definition and design. The platform makes use of advanced management tools to digitize information through the construction of IP rights projects. In order to give full play to the value of enterprise IP and further integrate it into the "knowledge engineering" project, it is necessary to collect knowledge templates, determine the knowledge representation method, and establish the knowledge base based on ontology. According to the collected templates, a new template suitable for IP can be combined, and the definition of computer language can be made clear to facilitate the analysis and screening of IP characteristics and attributes. Moreover, the extraction and exchange of information can realize the practice of further digging concept semantics, so as to meet the needs of knowledge retrieval. The realization of knowledge engineering needs to generate knowledge points from all kinds of original resources in the field of IP and complete the association analysis of knowledge, which is faced with specific technical problems of entity identification and attribute linkage, and the phenomenon of diversity, openness and ambiguity in the construction process is also an urgent problem to be solved.

\section{Cybersecurity}

With the rapid development of my country's commercial operation cloud platform, resource sharing and in-depth utilization are realized, economic growth is promoted, and new markets are opened up. The biggest feature of cloud storage is that storage is a service. Users can upload their data to the cloud for protection through a shared API. However, because users lose absolute control over data, some hidden data security risks have also arisen, that is, they are facing with more security challenges, the security issues of the TSITE platform have become increasingly prominent. Most users worry about data security when using operating service platforms, especially thirdparty platforms that use IoT data without authorization. If the cloud platform computing model is adopted, all user and intellectual property resource data are stored in the data center, which is difficult for users to control step by step. Unlike traditional resource collection and storage methods, the existing IP resource architecture has large capacity and many aspects. The new system structure brings corresponding security threats. As a new model, edge computing provides greater processing capabilities for platform terminals. However, there is a huge threat of private information leakage in collaboration services. Aiming at the problem of privacy leakage, intelligent offloading methods are proposed to achieve privacy protection. Technically, achieve the balance between privacy protection and system service performance. Even so, the existing research has many differences in the core security cognition and key functions of the platform, especially in data-driven applications, the trade-off between data availability and privacy, and traditional security technologies are difficult to meet the needs of platform dynamic operation [50-52]. Based on this, it is necessary to improve the security monitoring capabilities of the platform, crack the situation of resource utilization, and organize the formation of a platform security technical framework. Key technologies such as privacy protection and resource desensitization need to be solved in a breakthrough.

\section{Summary}

This section discusses the design, development and service mode of intellectual property platform from four aspects: legal services of intellectual property, comparison of specific industries, financial services and business resource services, and intellectual property operation service platform, and through cloud/edge computing, knowledge engineering, security and privacy. However, there are also deficiencies. The specific realization of intellectual property service mode and the technical realization of intellectual property platform need further investigation and research. In addition, the application of intellectual property in specific industries needs further investigation and summary.

\section{Conclusions}

On the basis of summarizing the current status of the current knowledge-driven distributed intellectual property operation service platform and intellectual property 
operation service model, the development of China's intellectual property operation service is discussed from the macro and micro levels. At the micro-level, detailed analysis is carried out from the perspective of legal, specific industry, financial support, and the differences in the resources provided by each platform; in addition, TSITE is mainly used as an example to analyze the design strategy of the intellectual property operation platform; and finally from the edge cloud computing system, knowledge engineering discuss the possibility of the future development direction of China's intellectual property operation service model with three aspects of network security. The conclusion is: the rapid development of China's intellectual property operation service platform must take a path that has Chinese characteristics and integrates with China's business environment. The government attaches great importance to intellectual property rights, and policy support provides a high-quality approach and general trend for this technological path. The success of the intellectual property operation service platform lies in its ability to provide universal market-oriented services acceptable to commercial customers. Private capital familiar with the business is most likely to win. Next, we will further investigate the specific implementation of the resource service mode of the intellectual property platform proposed in this paper. In addition, we will study and implement the implementation mode of the design strategy mentioned in this paper, and apply the cloud platform technology to the development of the intellectual property platforms.

\section{Abbreviations \\ IP: Intellectual Property; SIPOP: State Intellectual Property Operation Public Service Platform; SPV: Special Purpose Vehicle; STIS: Science and Technology Information Service}

\section{Acknowledgements}

Major Project of National Social Science Foundation of China (19ZDA078), "Research on the Mechanism and Path about Technological Standard and Intellectual Property Synergistically Promoting Digital Industry Innovation", NSSFC.

\section{Author's contributions}

The author has participated in conception and design, or analysis and interpretation of the data, drafting the article or revising it critically for important intellectual content, approval of the final version. The author read and approved the final manuscript.

\section{Author's information}

Yang Wang received the B.S in Administration from Nanjing University in 2009 and M.S. degree in science and technology entrepreneurship and innovation from Nanyang Technological University in Singapore in 2011. Now he is a doctor in the school of intellectual property of Nanjing University of technology. His major is management science and engineering, and his research interests include intellectual property strategy and innovation development. Besides, he is a member of Digital Innovation Management Committee of China Science and Technology Association.

\section{Funding}

Not applicable.

\section{Availability of data and materials}

The datasets generated and/or analysed during the current study are available in the [websites] repository, [http://www.sipop.cn/, https://www.bjiponline. com/home/index.html, http://www.iprun.com/en/, http://t-site.org/]

\section{Declarations}

\section{Ethics approval and consent to participate}

Not applicable.

\section{Competing interests}

The authors declare that they have no competing interests.

\section{Consent for publication}

Not applicable.

Received: 30 May 2021 Accepted: 23 November 2021

Published online: 11 December 2021

\section{References}

1. Sanchez-Cartas J (2021) Intellectual property and taxation of digital platforms. J Econ 132(3):197-221

2. Chen W, Zhou K, Fang W, Wang K, Bi F, Assefa B (2020) Review on blockchain technology and its application to the simple analysis of intellectual property protection. Int J Comput Sci Eng 22(4):437-444

3. Zhang J, Chen D, Liao J, Zhang W, Feng H, Hua G, Yu N (2021) Deep model intellectual property protection via deep watermarking. IEEE Trans Pattern Anal Mach Intell. https://doi.org/10.1109/TPAMI.2021.3064850

4. Ghamat S, Pun H, Critchley G, Hou P (2021) Using intellectual property agreements in the presence of supplier and third-party copycatting. Eur J Oper Res 291(2):680-692

5. Singh S (2018) The state of ip protection, exploitation and valuation: evidence from select indian micro, small and medium enterprises (msmes). J Entrep Innov Emerg Econ 4(2):159-176

6. Fang L, Lerner J, Wu C (2017) Intellectual property rights protection, ownership, and innovation: evidence from china. Rev Financial Stud 30(7):2446-2477

7. Grimaldi M, Greco M, Cricelli L (2021) A framework of intellectual property protection strategies and open innovation. J Bus Res 123:156-164

8. Zhang C (2020) Design and application of fog computing and internet of things service platform for smart city. Futur Gener Comput Syst 112:630-640

9. Wang Y, Gui H, Ma L (2020) A survey on services provision and distribution of official and commercial intellectual property platforms. Secur Commun Netw 2020(6):1-14

10. Mabrouki J, Azrour M, Fattah G, Dhiba D, El Hajjaji S (2021) Intelligent monitoring system for biogas detection based on the internet of things: Mohammedia, morocco city landfill case. Big Data Min Analytics 4(1):10-17

11. Ye Z, Zhao H, Zhang K, Wang Z, Zhu Y (2019) Network representation based on the joint learning of three feature views. Big Data Min Analytics 2(4):248-260

12. Zhang S, Pauwels K, Peng C (2019) The impact of adding online-to-offline service platform channels on firms' offline and total sales and profits. J Interact Mark 47:115-128

13. Efendioglu N, Woitsch R (2017) A modelling method for digital service design and intellectual property management towards industry 4.0: Caxman case. In: Int Conf Serviceology. pp 153-163

14. Lv Z, Li X, Wang W, Zhang B, Hu J, Feng S (2018) Government affairs service platform for smart city. Futur Gener Comput Syst 81:443-451

15. Grzegorczyk T (2020) Managing intellectual property: strategies for patent holders. J High Technol Manag Res 31(1):100374

16. Brander J, Cui V, Vertinsky I (2017) China and intellectual property rights: a challenge to the rule of law. J Int Bus Stud 48(7):908-921

17. Ren D, Song W, Ge Z, et al (2017) The study of agricultural intellectual property and intelligent agriculture development strategies in china. J Serv Sci Manag 10(3):230

18. Du W, Pan S, Zhou N, Ouyang T (2018) From a marketplace of electronics to a digital entrepreneurial ecosystem (dee): the emergence of a meta-organization in zhongguancun, china. Inf Syst J 28(6):1158-1175

19. Benassi M, Landoni M (2019) State-owned enterprises as knowledge-explorer agents. Ind Innov 26(2):218-241

20. Guo-Fitoussi L, Bounfour A, Rekik S (2019) Intellectual property rights, complementarity and the firm's economic performance. Int J Intellect Prop Manag 9(2):136-165 
21. Xiang D, Chen J, Tripe D, Zhang N (2019) Family firms, sustainable innovation and financing cost: evidence from chinese hi-tech small and medium-sized enterprises. Technol Forecast Soc Change 144:499-511

22. Al-Sharieh S (2021) The intellectual property road to the knowledge economy: remarks on the readiness of the uae copyright act to drive ai innovation. Law, Innov Technol 13(1):141-166

23. Huang K-L, Geng X, Wang H (2017) Institutional regime shift in intellectual property rights and innovation strategies of firms in china. Organ Sci 28(2):355-377

24. SIPOP. http://www.sipop.cn. Accessed 21 May 2021

25. IPOnline. https://www.bjiponline.com/home/index.html. Accessed 21 May 2021

26. Holgersson M, Granstrand O, Bogers M (2018) The evolution of intellectual property strategy in innovation ecosystems: uncovering complementary and substitute appropriability regimes. Long Range Plan 51(2):303-319

27. Chen $H$ (2017) New mode of intellectual property service promotes cid upgrade of zhongguancun. Zhongguancun 2017(4):46-49

28. Zhao R, Cao Y, Zheng X, Wang $H$ (2020) The innovation economy calls for proactive growth of intellectual property by various innovation carriers-a china case. Global Transit Proc 1(1):23-31

29. Lai P (2018) Research, innovation and development strategic planning for intellectual property management. Econ Altern 2018(3):303-310

30. CIPRUN GROUP. http://www.iprun.com/en. Accessed 21 May 2021

31. Teixeira A, Ferreira C (2019) Intellectual property rights and the competitiveness of academic spin-offs. J Innov Knowl 4(3):154-161

32. TSITE. http://t-site.org. Accessed 21 May 2021

33. Chen Y, Pereira I, Patel $P(2021)$ Decentralized governance of digital platforms. J Manag 47(5):1305-1337

34. Sekerin V, Slepov V, Gayduk V, Bank S, Kravets E (2021) Blockchain technology development as tool for enhancing security in management and protection of intellectual property rights in additive manufacturing. Revista Gestão Inovação e Tecnologias 11(2):1184-1200

35. Feng $\mathrm{S}, \mathrm{Ma} X$ (2019) To increase damages of intellectual property infringement in china: a double-edged sword for the market. J World Trade 53(1):39-58

36. Hou K, Zhang M (2021) Discussion on legal model of intellectual property of computer software. In: Journal of Physics: Conference Series, vol. 1883. IOP Publishing, IOP Science. p 012011

37. Gurkaynak G, Ylmaz I, Doygun T, İnce E (2017) Questions of intellectual property in the artificial intelligence realm. Robot Law J 3(2):9-11

38. Gomez-Barquero D, Lee J-Y, Ahn S, Akamine C, He D, Montalaban J, Wang J, Li W, Wu Y (2020) leee transactions on broadcasting special issue on: convergence of broadcast and broadband in the $5 \mathrm{~g}$ era. IEEE Trans Broadcast 66(2):383-389

39. Guo F (2020) Research on college students' entrepreneurship policy under the background of $5 \mathrm{~g}$ era and intellectual property rights. Chin Foreign Enterp Cult 606(5):120-122

40. Li C, Zhu P (2019) Thinking on the construction of intellectual property protection in scientific and technological innovation enterprises. Technol Econ Guide 27(29):216-217

41. Cui Q (2020) Prospect of chinese patents from $5 \mathrm{~g}$ technology. Technol Innov Appl 2020(8):13-14

42. Liu Y (2019) Research on the construction of financial system to promote the achievement transformation of scientific and technological enterprises. Technol Innov Appl 2019(9):10-11

43. Yin Y (2016) Accelerating the construction of china's financial system supporting technological innovation. Macroecon Res 2016(7):13-20

44. Li E (2019) Building an intellectual property financial service platform based on blockchain technology to promote economic development from factor driven to innovation driven. Wealth era 174(11):23-24

45. Xu X, Huang Q, Yin X, Abbasi M, Khosravi M, Qi L (2020) Intelligent offloading for collaborative smart city services in edge computing. IEEE Internet Things J 7(9):7919-7927

46. Bi R, Liu Q, Ren J, Tan G (2020) Utility aware offloading for mobile-edge computing. Tsinghua Sci Technol 26(2):239-250

47. Qi L, Song H, Zhang X, Srivastava G, Xu X, Yu S (2021) Compatibility-aware web api recommendation for mashup creation via textual description mining. ACM Trans Multimidia Comput Commun Appl 17(1s):1-19

48. Zhang Z, Cong X, Feng W, Zhang H, Fu G, Chen J (2020) Waeas: An optimization scheme of eas scheduler for wearable applications. Tsinghua Sci Technol 26(1):72-84
49. Chen N, Wang Z, He R, Jiang J, Cheng F, Han C (2021) Efficient scheduling mapping algorithm for row parallel coarse-grained reconfigurable architecture. Tsinghua Sci Technol 26(5):724-735

50. Mabrouki J, Azrour M, Dhiba D, Farhaoui Y, El Hajjaji S (2021) lot-based data logger for weather monitoring using arduino-based wireless sensor networks with remote graphical application and alerts. Big Data Min Analytics 4(1):25-32

51. Qi L, Wang X, Xu X, Dou W, Li S (2020) Privacy-aware cross-platform service recommendation based on enhanced locality-sensitive hashing. IEEE Trans Netw Sci Eng PP(99):1. https://doi.org/10.1 109/TNSE.2020.2969489

52. Xu X, Huang Q, Zhu H, Sharma S, Zhang X, Qi L, Bhuiyan M (2020) Secure service offloading for internet of vehicles in sdn-enabled mobile edge computing. IEEE Trans Intell Trans Syst 22(6):3720-3729

\section{Publisher's Note}

Springer Nature remains neutral with regard to jurisdictional claims in published maps and institutional affiliations.

\section{Submit your manuscript to a SpringerOpen ${ }^{\circ}$ journal and benefit from:}

- Convenient online submission

- Rigorous peer review

- Open access: articles freely available online

- High visibility within the field

- Retaining the copyright to your article

Submit your next manuscript at $\boldsymbol{\wedge}$ springeropen.com 